\title{
Iridium-Catalyzed Isomerization of Primary Allylic Alcohols
}

\author{
Luca Mantilli and Clément Mazet*
}

\begin{abstract}
A readily accessible iridium hydrogenation catalyst displays high reactivity for the isomerization of primary allylic alcohols under mild reaction conditions. Key to the efficiency of the catalytic system is to deviate from the conventional hydrogenation route in favor of the desired isomerization pathway by adequately tuning the reaction conditions as indicated by preliminary mechanistic investigations.
\end{abstract}

Keywords: Allylic alcohols · Homogeneous catalysis · Iridium · Isomerization

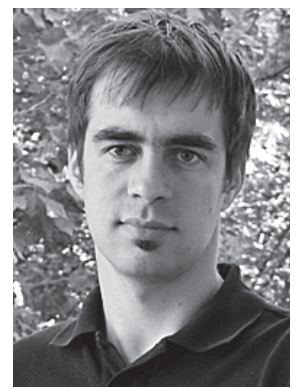

After two years of undergraduate studies in the laboratory of the late Prof. John A. Osborn, University of Strasbourg (France), Clément Mazet carried out his $\mathrm{PhD}$ research work under the guidance of Prof. Lutz H. Gade at the same university. In 2003, he moved to Basel where he worked as a post-doctoral fellow in the group of Prof. Andreas Pfaltz. In 2006 he was awarded a Marie Curie International Outgoing Fellowship and spent nearly two years working with Prof. Eric. N. Jacobsen at Harvard University (USA). He joined the Organic Chemistry Department of the University of Geneva in November 2007. His research interests include mechanistic and synthetic chemistry with particular emphasis on asymmetric catalysis.

\footnotetext{
${ }^{\star}$ Correspondence: Dr. C. Mazet

University of Geneva

Department of Organic Chemistry

Quai Ernest Ansermet 30

$\mathrm{CH}-1211$ Geneva

Tel.: +4122 3796288

Fax: + 41223793215

E-mail: clement.mazet@unige.ch
}

The isomerization of primary and secondary allylic alcohols to the corresponding aldehydes and ketones is a reaction of significant synthetic value.[1] Interested by the high versatility of aldehydes, we have recently initiated a research program to investigate this transformation. To date, there is no general and practical catalyst that functions under mild reaction conditions and displays a wide substrate generality, in particular for less reactive primary allylic alcohols with sterically hindered and/or highly substituted olefins. ${ }^{[1,2]}$ This is somewhat surprising regarding the level of achievement attained for the related isomerization of allylic amines to enamines, a reaction that stands out as one of the most studied, understood and accomplished processes in homogeneous catalysis. ${ }^{[3]}$

In transition metal-catalyzed hydrogenation reactions, undesired isomerization of the reacting olefin is the most common competing process. Increasing the hydrogen pressure or tuning the steric and electronic requirements of the surrounding ligands usually leads to partial or complete suppression of this side-reaction. ${ }^{4]} \mathrm{We}$ initially reasoned that, under appropriate experimental conditions, certain hydrogenation catalysts may preferentially follow a productive isomerization pathway rather than the hydrogenation route. ${ }^{[2]}$ Herein, we report the identification of a highly active catalyst that promotes the isomerization of diverse primary allylic alcohols under very mild reaction conditions.

Although numerous transition metals have been investigated, rhodium and ruthenium catalysts clearly dominate the field of the isomerization of allylic alcohols. ${ }^{[1,2]}$ We were initially interested in testing the commercially available cationic iridium complex $\left[\left(\mathrm{Cy}_{3} \mathrm{P}\right)(\right.$ pyridine $\left.) \operatorname{Ir}(\mathrm{COD})\right] \mathrm{PF}_{6} \mathbf{1}$ $(\mathrm{COD}=1,5$-cyclooctadiene $)$ - also known as the Crabtree catalyst - because it is a potent hydrogenation catalyst in particu- lar for less reactive densely substituted unfunctionalized alkenes. ${ }^{[5]}$ In addition, Stork and Kahne ${ }^{[6]}$ and Crabtree and Davies $^{[7]}$ have convincingly demonstrated that $\mathbf{1}$ is effective in the directed reduction of cumbersome allylic alcohols and homoallylic alcohols. Nevertheless, previous attempts to use this catalyst in exclusive isomerization of olefins have proven elusive since the high loadings usually employed (10-20 mol\%) lead to reproducibility ${ }^{[8]}$ and/or selectivity ${ }^{[9]}$ issues. In hydrogenation reactions, the bulky, highly lipophilic, $\left.\mathrm{BAr}_{\mathrm{F}}^{-}\left(\mathrm{B}\left[\left(3,5-\left(\mathrm{CF}_{3}\right)_{2}\right) \mathrm{C}_{6} \mathrm{H}_{3}\right)_{4}\right]^{-}\right)$ counter-anion was shown to favor olefin coordination and to slow down deactivation processes due to very weak and noncompetitive ion-pairing interactions. ${ }^{[10,11]}$ Superior catalytic performances of $\mathbf{2}$ over $\mathbf{1}$ in hydrogenation reactions have been independently reported by Buriak and coworkers ${ }^{[10 \mathrm{c}]}$ and Pfaltz and coworkers. ${ }^{[10 \mathrm{e}]}$

Our preliminary investigations started with a comparative study of catalysts $\mathbf{1}$ and $\mathbf{2}$ for the isomerization of primary allylic alcohols. As anticipated, the experimental set-up of the reaction turned out to be crucial for the success of the process. Activation of the precatalysts by hydrogenating off the cyclooctadiene co-ligand was performed by bubbling molecular hydrogen directly through the solution followed by two freeze-pump-thaw cycles to extrude the excess of hydrogen gas from the reaction media prior to substrate addition. Reactions were carried out using (E)-4methyl-3-phenyl-2-pentenol as model substrate in THF at room temperature and 5 mol\% of precatalyst (Scheme 1). Crabtree catalyst analogue $\mathbf{2}$ afforded the aldehyde quantitatively while the original Crabtree catalyst 1 gave only $74 \%$ of the isomerization product. In both cases no saturated alcohol was detected. If the substrate was added before activation of the precatalyst or, if the hydrogen atmosphere was maintained throughout the reaction, partial or 


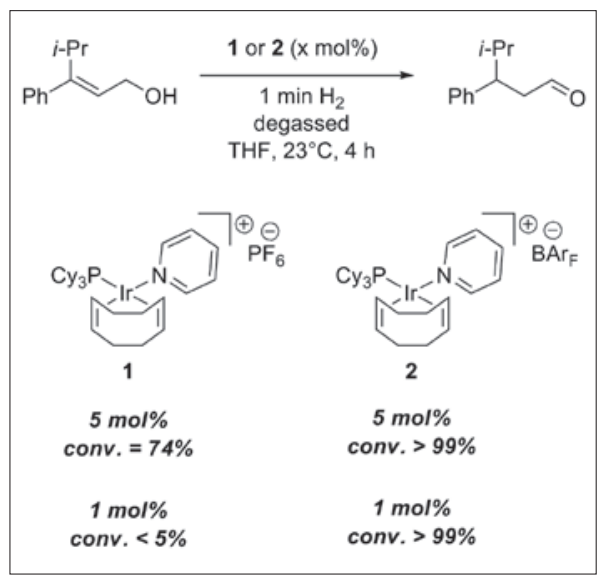

Scheme 1. Comparative study between 1 and 2 for the isomerization of (E)-4-methyl-3phenyl-2-pentenol as model substrate.

complete hydrogenation of the substrate was observed respectively. When reducing the catalyst loading down to $1 \mathrm{~mol} \%$, catalyst 2 still furnished the desired aldehyde quantitatively whereas a complete loss of activity was observed for $\mathbf{1}$.

The scope of the isomerization reaction using catalyst $\mathbf{2}$ was investigated next (Scheme 2). 3,3-Dialkyl-substituted aldehydes were obtained from the corresponding allylic alcohols 3-6 using low catalyst loadings $(0.25-1.0 \mathrm{~mol} \%)$ in very short reaction time (0.5-2 h). Using $5 \mathrm{~mol} \%$ of 2 for the isomerization of the sterically more demanding (E)-3,4,4-trimethylpent-2-enol 7 afforded quantitatively the desired product within 16 h. Cinnamyl alcohol 8 and analogous electron-rich heterocycles $\mathbf{1 5}$ and $\mathbf{1 6}$ also reacted under very mild conditions. Less reactive analogues 9-12 bearing an additional 3-alkyl substituent required slightly increased amount of catalyst as well as reaction time to undergo complete conversion. Substrates with a 2,3-substitution pattern reacted in a contrasted manner, presumably reflecting the relative stability of the enols. Whereas a methyl group on the 2-position (13) readily produces the expected $\alpha$-substituted aldehyde, a phenyl ring (14) considerably decelerates the reaction and requires higher loadings of catalyst. Finally, under more forcing conditions $\left(10 \mathrm{~mol} \%\right.$ of $\left.2,65^{\circ} \mathrm{C}\right)$, allylic alcohol 17 with a tetrasubstituted olefin was converted to a 1:1 mixture of cis and trans isomerization products.

Activation of $(\mathrm{P}, \mathrm{N})$-iridium complexes by molecular hydrogen generates intermediates of type 19 where both hydrides are located cis to the $\mathrm{P}$ atom (Scheme 3). ${ }^{[4,12,13]}$ According to our initial hypothesis, discrimination between hydrogenation and isomerization pathways is expected to arise from intermediates 20a and 20b depending whether migratory insertion occurs preferentially at $\mathrm{C}(2)$ or at $\mathrm{C}(3)$ respectively.

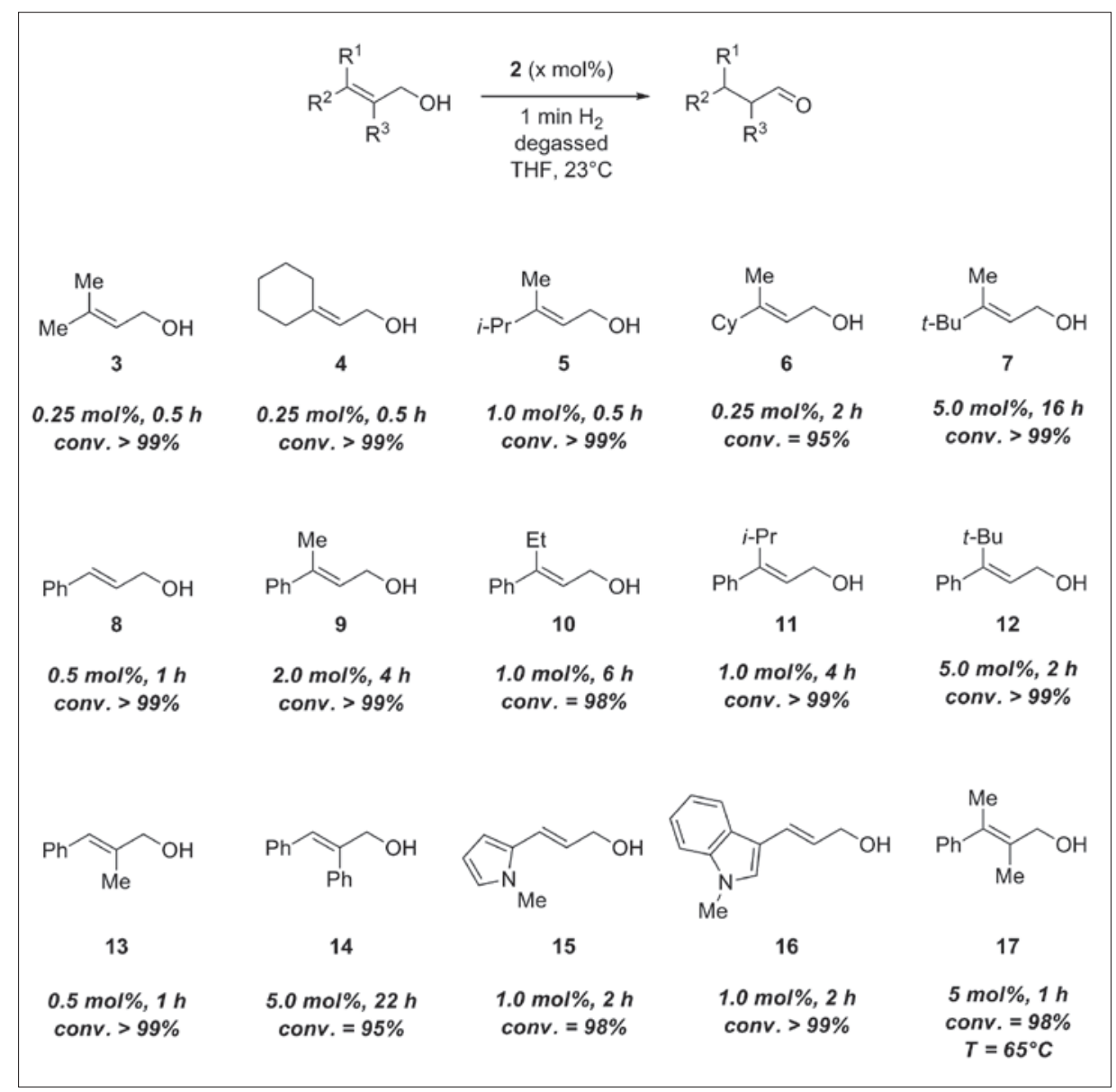

Scheme 2. Scope of the isomerization reaction using 2.

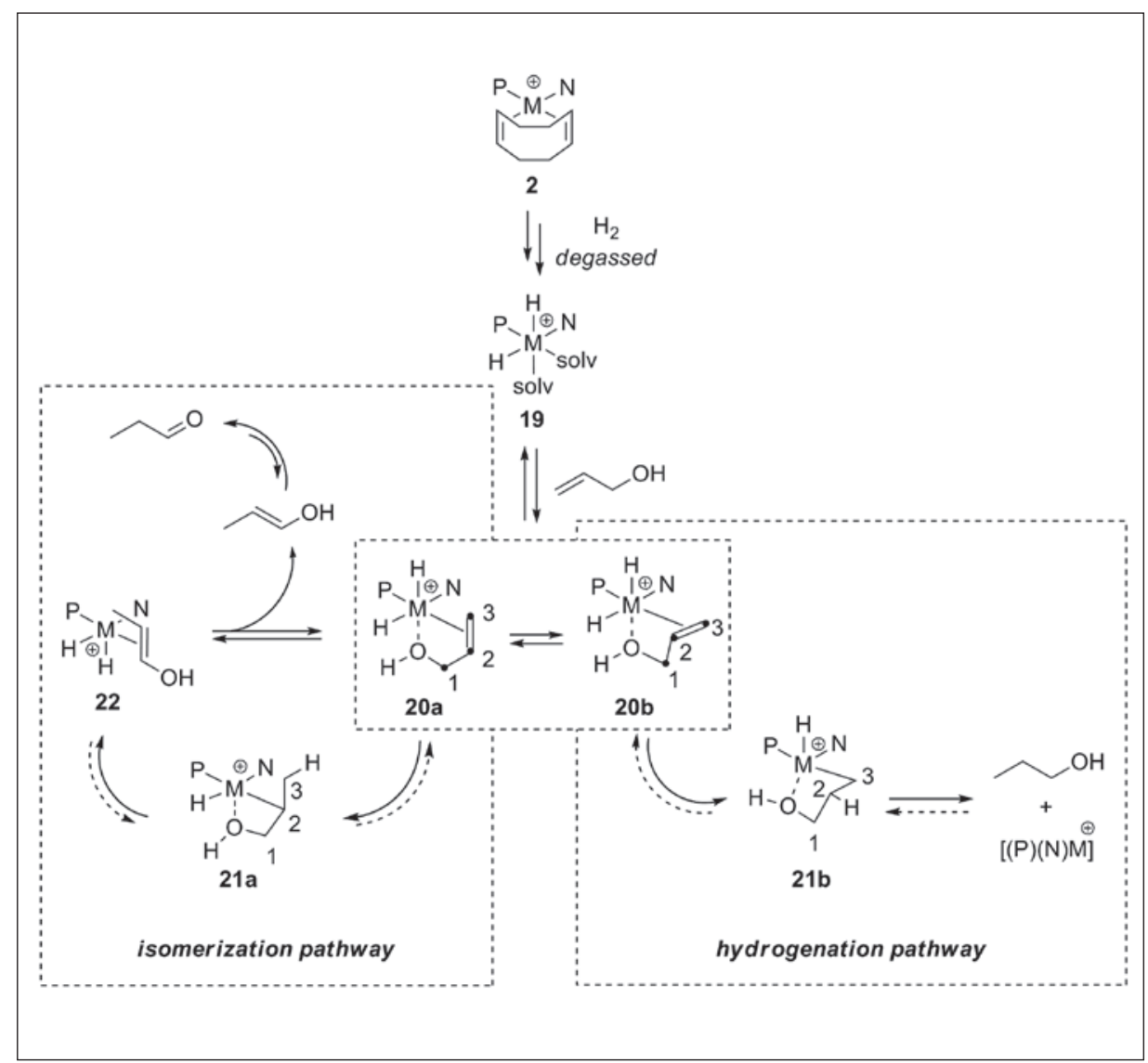

Scheme 3. Mechanistic hypothesis. 


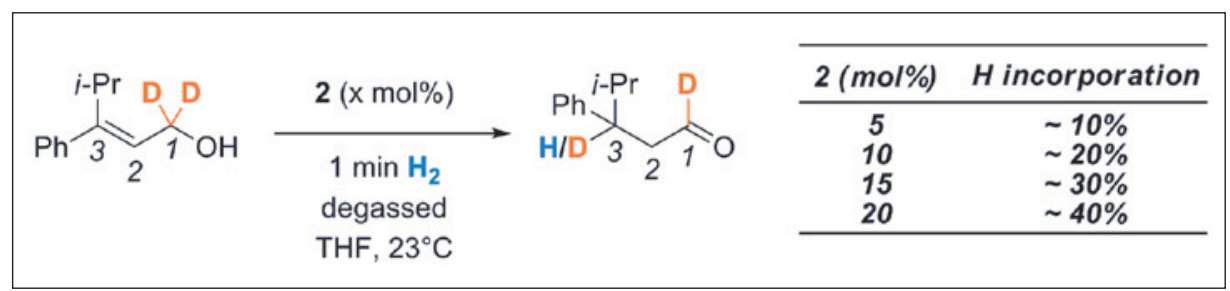

Scheme 4. Labeling experiments.

Labeling experiments using 1,1-dideuterated model substrate and variable loadings of complex $\mathbf{2}$ were carried out under standard conditions (Scheme 4). In each case, monodeuterated aldehyde, indicative of an intermolecular process, was unequivocally observed by EI-HRMS. Furthermore, ${ }^{1} \mathrm{H}$ NMR analysis of the crude reaction mixtures recorded after complete conversion showed exclusive incorporation of hydrogen at $\mathrm{C}(3)$ was twice proportional to the initial loading in $\mathbf{2}$. Complete transfer of hydrogen to the product implicates rapid exchange between the two hydrides in 19. This was independently confirmed by $2 \mathrm{D}$ ROESY experiments measured in the hydride region $(-15$ to $-35 \mathrm{ppm})$ after generating 19 in THF- $\mathrm{d}_{8}$ and degassing. In addition, if the substrate coordinates via both the olefin and the hydroxyl group as demonstrated by Stork ${ }^{[6]}$ and Crabtree ${ }^{[7]}$ in their hydrogenation studies, the binding of the alcohol must be reversible to allow $\beta$ - $\mathrm{H}^{1}$-elimination in the isomerization pathway (21a 22, Scheme 3).

In conclusion, we have designed an experimental protocol that revealed the ability of an air-stable Crabtree catalyst analogue $\mathbf{2}$ to promote cleanly the isomerization of a wide range of primary allylic alcohols in the corresponding aldehydes. Reactions were run at room temperature with appreciable reaction rates using low cata- lyst loadings (0.25-5.0 mol\%). Unprecedented isomerization of a primary allylic alcohol with a tetrasubstituted olefin was achieved using higher catalyst loading and temperature. Preliminary investigations support our initial mechanistic hypothesis. The catalyst stability and accessibility as well as the generality of the process and the mild reaction conditions augur well for

\section{Acknowledgments}

Financial support from the University of Geneva is gratefully acknowledged. We thank D. Gérard and S. Torche for assistance in synthesis, and B. Vitorge and A. Pinto for assistance in NMR measurements. JohnsonMatthey is also thanked for generous loan of iridium precursors.

Received: January 5, 2009

[1] For recent reviews, see: a) R. C. Van der Drift, E. Bouwman, E. Drent, J. Organomet. Chem. 2002, 650, 1; b) R. Uma, C. Crévisy, R. Grée, Chem. Rev. 2003, 103, 27; c) V. Cadierno, P. Crochet, J. Gimeno, Synlett 2008, 8, 1105. For relevant examples, see: d) S. Bergens, B. Bosnich, J. Am. Chem. Soc. 1991, 113, 958; e) K. Tanaka, S. Qiao, M. Tobisu, M. M.-C. Lo, G. C. Fu, J. Am. Chem. Soc. 2000, 122, 9870; f) R. Uma, M. K. Davies, C. Crévisy, R. Grée, Eur. J. Org. Chem. 2001, 3141; g) B. MartinMatute, K. Bogár, M. Edin, F. B. Kaynak, J. E. Bäckvall, Chem. Eur. J. 2005, 11, 5832; h) V. Cadierno, S. E. García-Garrido, J. Gimeno, A. Varela Álvarez, J. A. Sordo, J. Am. Chem. Soc. widespread use of this method.
2006, 128, 1360; i) M. T. Reetz, G. Hougchao, Synlett 2006, 13, 2127.

[2] For mechanistic studies, see: a) B. M. Trost, R. J. Kuliawec, J. Am. Chem. Soc. 1993, 115,2027 ; b) D. V. McGrath, R. H. Grubbs, Organometallics 1994, 13, 224; c) K. Tanaka, G. C. Fu, J. Org. Chem. 2001, 66, 8177.

[3] a) For a review, see: S. Akutagawa, in 'Comprehensive Asymmetric Catalysis', Eds. E. Jacobsen, A. Pfaltz, H. Yamamoto, Springer, Berlin, 1999; Vol. 3, Chapter 41.4. Seminal contribution: b) K. Tani, K. Pure Appl. Chem. 1985, 57, 1845. Mechanistic studies: c) S. Inoue, H. Takaya, K. Tani, S. Otsuka, T. Sato, R. Noyori, J. Am. Chem. Soc. 1990, 112, 4897.

[4] a) R. R. Schrock, J. A. Osborn, J. Am. Chem. Soc. 1976, 98, 2134; b) C. S. Chin, J. H. Shin, C. Kim, J. Organomet. Chem. 1988, 356, 381 c) Y. Sun, R. N. Landau, J. Wang, C. LeBlond, D. G. Blackmond, J. Am. Chem. Soc. 1996, 118, 1348.

[5] R. H. Crabtree, Acc. Chem. Res. 1979, 12, 331.

[6] G. Stork, D. Kahne, J. Am. Chem. Soc. 1983, 105, 1072.

[7] R. H. Crabtree, M. W. Davis, Organometallics 1983, 2,681

[8] D. Baudry, M. Ephritikhine, H. Felkin, Nouv. J. Chem. 1978, 2, 355.

[9] a) M. Krel, J.-Y. Lallemand, C. Guillou, Synlett 2005, 13, 2043; b) Y. Kavanagh, C. M. Chaney, J. Muldoon, P. Evans, J. Org. Chem. 2008, 73, 8601

[10] a) M. Brookhart, B. Grant, A. F. Volpe, Organometallics 1992, 11 3920; b) S. P. Smidt, N. Zimmermann, M. Studer, A. Pfaltz, Chem. Eur. J. 2004, 10, 4685; c) L. D. Vazquez-Serano, B. T. Owens, J. M. Buriak, Inorg. Chim. Acto 2006, 359, 2786; d) D. Nama, P. Butti, P. S. Pregosin, Organometallics 2007, 26, 4942; e) B. Wüstenberg, A. Pfaltz, Adv. Synth. Catal. 2008, 350, 174.

[11] a) D. F. Chodosh, R. H. Crabtree, H. Felkin, G. E. Morris, J. Organomet. Chem. 1978, 161, C67; b) H. Wang, A. L. Casalnuovo, B. J. Johnson, A. M. Mueting, L. H. Pignolet, Inorg. Chem. 1988, 27, 325; c) Y. Xu, D. M. P. Mingos, J. M. Brown, Chem. Commun. 2008, 199.

[12] a) X. Cui, K. Burgess, Chem. Rev. 2005, 105, 3272; b) S. J. Roseblade, A. Pfaltz, Acc. Chem. Res. 2007, 40, 1402.

[13] R. H. Crabtree, P. C. Demou, D. Eden, J. M Mihelic, C. A. Parnell, J. M. Quirk, G. E. Morris, J. Am. Chem. Soc. 1982, 104, 6994. 